\title{
Recurrent Pancreatic Ductal Adenocarcinoma
}

National Cancer Institute

\section{Source}

National Cancer Institute. Recurrent Pancreatic Ductal Adenocarcinoma. NCI Thesaurus.

Code C153619.

The reemergence of pancreatic ductal adenocarcinoma after a period of remission. 